Reeve, D. (2002) 'Negotiating psycho-emotional dimensions of disability and their influence on identity constructions', Disability \& Society 17(5): 493-508.

This is the corrected version incorporating reviewer comments and has been paginated to match the published version. Small typographical differences may therefore exist between this and the published version.

\title{
Negotiating Psycho-Emotional Dimensions of Disability and their Influence on Identity Constructions
}

\begin{abstract}
This paper uses Foucault's concept of 'technologies of power' to explore the ways in which the psycho-emotional dimensions of disability are created and maintained within society. The manner in which gaze and self-surveillance operate on the bodies of people with impairments to leave them feeling worthless, unattractive and stressed is considered and the effects of impairment on these processes are also discussed. However disabled people are not simply passive victims of this form of emotional disablism - many exercise agency and resist. The manner in which disabled people resist the negative stereotypes is described and the process of 'coming out' as a disabled person is offered as an example of a 'technology of the self'. This interplay of dominating and emancipatory forces is shown to contribute to a disability identity which is fluid and which better represents the diversity of the disability experiences of disabled people than an essentialist disability identity.

\section{Introduction}

Disability theory owes much to Marxism, feminism and postmodernism, although at times these different perspectives also threaten to destroy this relatively new discipline (Corker 1999b). Many of the debates centre around interpretations of the social model of disability. Recently, in response to some of these criticisms, Thomas (1999a) proposed an extended social relational understanding of disability to include both structural and psycho-emotional dimensions of disability. This latter form of disablism undermines the emotional well-being of disabled people and can be just as disabling as structural barriers. Discussions about the psychological effects of exclusion, discrimination and prejudice are important because
\end{abstract}

'[d]ealing with anger, self-loathing, and daily experiences of rejection and humiliation are among the hardest aspects of being a disabled person' (Shakespeare, et al. 1996: 42-43).

At the same time as disability studies appears to be removing the body from 
sociological analysis, sociology has rediscovered the body (Hughes and Paterson 1997). Foucault can be described as one of the most significant theorists of the body, in how it has been constituted with respect to power rather than in biological terms (Fox 1993). However, despite the importance of Foucault's work within contemporary social theory, the use of his ideas within disability studies is relatively scarce (Hughes and Paterson 1997). Over the last few years Foucauldian concepts have been applied within this discipline to theorise a sociology of impairment (Hughes 1999; Hughes and Paterson 1997) and to attempt to challenge the disability/impairment and disabled/able-bodied dichotomies (Corker and French 1999a; Price and Shildrick 1998). In addition Foucault's work has been drawn upon to understand the experiences of children with Special Educational Needs (Allan 1996) and the ways in which discourses grounded in the medical model affect the services disabled people receive (Chadwick 1996; McIntosh 2002; Sullivan and Munford 1998). It is my intention to extend the use of Foucauldian concepts within disability studies to include a discussion of the psycho-emotional dimensions of disability, building on the existing literature which focuses mainly on the structural dimensions of disability.

In this paper I will use the Foucauldian themes of power, knowledge and subjectivity to explore the ways in which the psycho-emotional dimensions of disability are created and maintained within society and how in turn these are challenged by disabled people. In particular I will be considering the effects of different forms of power/knowledge acting on the impaired body. The experience of psycho-emotional disablism is not inevitable because disabled people can resist the technologies of power imposed from above and may also transform themselves by 'coming out' as a disabled person - reclaiming disability as a positive identity. Finally I draw on my discussions of the psycho-emotional dimensions of disability to show how this form of disability contributes to a disability identity which is fluid and diverse.

An exploration of the psycho-emotional dimensions of disability is long overdue. This form of disablism saps the strength of disabled people, and in the absence of any structural disability within society, would still prevent them from being the people they have the potential to be. Understanding this important area of disability is not just about self-preservation, it also exposes the power relations between disabled and non-disabled people (Keith 1996).

\section{Psycho-emotional dimensions of disability}

The social model of disability posits disability as being caused by 'externally imposed disadvantage and social restriction' (Oliver and Barnes 1998: 18) rather than impairment. This shift to make disability a social, rather than individual problem has been a vital part of the move towards the emancipation of disabled people within society. However this definition of disability has been criticised for failing to acknowledge the role played by impairment and illness in the life experiences of disabled people (Crow 1996; French 1993; Morris 1991) and for placing 
too much emphasis on socio-structural barriers, thereby ignoring the cultural and experiential dimensions of disability (Shakespeare 1994).

Another criticism of the social model of disability is that the focus has been on the 'public' experiences of oppression such as social barriers, at the expense of the more 'personal' experiences of oppression which operate at the emotional level (Thomas 1999a). In addition to the socio-structural barriers and restrictions which exclude and discriminate against disabled people, Thomas (1999a) suggests that the social model of disability should be extended to include social processes and practices which undermine the emotional well-being of people with impairments. These psycho-emotional dimensions of disability which affect what disabled people can be, rather than what they can do, include being hurt by the reactions of other people, being made to feel worthless and unattractive and have their roots in the negative attitudes and prejudices about disabled people within society.

There are various manifestations of the psycho-emotional dimensions of disability. One important aspect includes the way in which disabled people respond emotionally to social exclusion and physical barriers (structural disability), such as feelings of anger and frustration when faced with inaccessible buildings. Another dimension of this form of disability includes the emotional responses to the social reactions of other people, for example, feeling ashamed when being stared at in the street. An important element of this type of emotional disablism is called internalised oppression and is a feature of any marginalised group within society. It can be described as the:

'incorporation and acceptance by individuals within an oppressed group of the prejudices against them within the dominant society ... [and] the mechanism within an oppressive system for perpetuating domination not only by external control but also by building subservience in to the minds of the oppressed groups' (Pheterson 1986: 148).

One example of internalised oppression is when a disabled person believes that they do not have the right to be a sexual being, having internalised the prejudice that disabled people are asexual (Morris 1991).

The personal psychological effects of internalised oppression experienced by disabled people have been described graphically, for example,

'We harbour inside ourselves the pain and the memories, the fears and the confusions, the negative self-images and the low expectations, turning them into weapons with which to re-injure ourselves, every day of our lives' (Mason 1992: 27).

Psychoanalysis, in the form of object relations theory, explains internalised oppression as the projection of the disavowed parts of non-disabled people onto disabled people who are constituted as Other (Shakespeare 1994). Whilst this explanation implies that internalised oppression is an inevitable experience for all disabled people, I do not believe that all disabled people experience the same levels of internalised oppression because they are not a homogenous group. Woolley (1991) described how the experience of oppression and internalised oppression was 
different for someone like herself who became deaf, as opposed to someone who was born deaf into the Deaf community. There is also anthropological evidence of some societies in which people with impairments were not rejected or excluded (Barnes 1997).

Despite the prevalence of negative stereotypes of disability within all aspects of society and the damaging effects internalised oppression has on the everyday life of disabled people, this phenomenon remains a currently neglected area of discussion within disability studies (Marks 1999). Part of the reason for this neglect is that psychology has been criticised for pathologising disability (Oliver 1990) and psychoanalysis has been rejected for being based within a medical model approach to disability - thus aspects of the experience of disabled people which affect their emotional well-being have been ignored. However the extension of the social relational understanding of disability to include both structural and psycho-emotional dimensions of disability provided by Thomas (1999a) offers a way of opening up discussion about internalised oppression and other emotional experiences linked to the experience of disability.

For the remainder of this paper I will contribute to this discussion about the psycho-emotional dimensions of disability by applying Foucauldian perspectives to this form of disablism. Internalised oppression relies on disabled people internalising the prejudices and stereotypes held by a non-disabled majority; this relates nicely to a Foucauldian analysis of the ways in which 'regimes of truth' about disabled bodies affect their governance and control. As the corporeal body is inseparable from the power inscribed on it, considering the nature of the lived body/impairment exposes the embodied experience of prejudice, oppression and discrimination (Hughes and Paterson 1997), or in other words, the experience of the psycho-emotional dimensions of disability.

As well as identifying particular 'technologies of power' which underpin some of this emotional form of disablism, I will also consider how Foucault's concept of the more creative 'technologies of the self' can reveal the ways in which disabled people can resist and challenge the psycho-emotional dimensions of disability. Finally I will discuss the ways in which 'subjectivity' can be linked to the experiences of this psycho-emotional form of disablism and how this relates to the identity of disabled people. However, I will first provide a brief description of some of the fundamental Foucauldian concepts I will be using throughout this paper.

\section{Foucault - themes of power, knowledge and subjectivity}

Foucault provided a definition of power which was in direct contrast to that used within traditional concepts of capitalism. Instead of monolithic control or power being held by a clearly defined group within society, he instead described power as being induced in the body and produced within every human relationship with 'relations of power' being the key point (Foucault 2000a). Power is never localised in the hands of one person but instead permeates throughout with individuals being the 'vehicles of power, not its points of application' (Foucault 1980b: 98).

Foucault's historical analysis of the shift from sovereign power to a more 
pervasive disciplinary power highlights its productive, constitutive nature (Williams and Bendelow 1999). Disciplinary power classifies and documents individuals and places them under continuous forms of surveillance; this power turns its subjects into objects of power/knowledge (Foucault 1977). Power and knowledge are intimately interlinked - it is not possible to have one without the other (Foucault 1980a). In addition the concept of power/knowledge was developed by Foucault to illustrate how knowledge is what makes people subjects because they make sense of themselves (and others) by referring back to various bodies of knowledge (Danaher, et al. 2000: 50).

The use of disciplinary power to render a body docile, and therefore productive and economically useful, entails the creation of procedures of normalisation against which to monitor that body. Foucault showed that medicine and psychoanalysis, in addition to the penal system, provided examples of disciplinary and regulatory controls leading to the creation of new norms (Foucault 1971; 1976). This diffusion of the medical discourse has enabled the medical model view of disability to become widespread at all levels of society, affecting the manner in which institutions from the government to industry treat disabled people (Chadwick 1996). The widespread institutional use of this particular model of disability makes it almost immune to challenge as seen in the Disability Discrimination Act (1995) which uses a definition of disability based on the medical, rather than social model of disability.

A Foucauldian concept of power is not only negative, resulting in prohibition and exclusion; the most important product to be created from power is resistance to that power and Foucault believed that if there were no resistance, then there would be no power relations (Foucault 2000a). A major criticism of Foucault's work has been the inability to satisfactorily explain resistance (Williams and Bendelow 1999). In his earlier works Foucault appears to provide a rather pessimistic view about the possibility of radical resistance and it was only in his later works that the role of individual agency was included in his concepts of the 'technologies of the self'; these internalised procedures

'permit individuals to effect by their own means, or with the help of others, a certain number of operations on their own bodies and souls, thoughts, conduct, and way of being, so as to transform themselves in order to attain a certain state of happiness, purity, wisdom, perfection or immortality' (Foucault 2000b: 225).

The technologies of the self have a potential for emancipatory action because of the individual's capacity for autonomy, reflexivity and critique (McNay 1992). The technologies of the self also aimed to overcome some of the more negative connotations of disciplinary power and docile bodies which implied that people were completely dominated by and subject to power (Williams and Bendelow 1999). However Foucault also admitted that these technologies of the self were not as liberating as the above poetic quote would imply (Foucault 2000a); such a creation of the self is also subject to restrictions imposed by culture and other people within society.

Related to power and knowledge is the final theme of subjectivity, which is used 
to explain identity, or the self. Subjectivity is not a static characteristic; it is created by the ever-changing interaction of discourses, institutions and relations (Danaher, et al. 2000). As the construction of subjectivity is through power/knowledge, people are formed as subjects from above by technologies of power, but this is modified by the ways in which individuals oppose these relations of power (resist) or transform themselves (technologies of the self) (Foucault 2000b). Subjectivity is also dependent on the context - people constitute themselves as different subjects depending on whether they are going to vote or are seeking a sexual relationship with a partner (Foucault 2000a: 290). Therefore subjectivity is a fluid identity, affected by time and place, culture and society.

\section{Technologies of power exposed within the psycho-emotional dimensions of disability}

The Foucauldian themes of power, knowledge and subjectivity are interlinked and I will now consider how two technologies of power which regulate the body gaze and self-surveillance - can illuminate the processes behind psychoemotional disablism before considering how disabled people can resist this form of disability.

\section{Gaze}

Through this technology of power, the object of the gaze becomes known to the viewer and the observer gains expertise and control over those being gazed at. This can be seen in institutional settings where bodies are disciplined medicine, psychiatry, law, education and social work (Fox 1993). For disabled people, the body truly has become a site of power/knowledge under the surveillance of medical experts who use the clinical gaze to identify deviance and disorder and to constitute the subject as a patient (Fox 1993). The phenomenon known as 'public stripping' (French 1994b: 104) is a direct form of the clinical gaze which leaves the recipient feeling vulnerable, exposed and humiliated and is an example of a psycho-emotional form of disability as well as a form of institutional abuse.

Whilst medicalisation has improved, and even saved the lives of many disabled people who would have died a century ago (such as people with spinal cord injury Oliver, et al. 1988), there is a darker side to the gaze of medicine. Medical techniques increasingly penetrate and inscribe the body, from X-rays to foetal screening; at the same time medicine has become a political enterprise with decisions about treatment being affected by finances and government election promises. Good examples of this bio-power are the ways in which foetuses with a perceived impairment are regularly terminated (Bailey 1996) and the recent outcry over the use of Do Not Resuscitate notices on elderly and disabled people in hospitals (Wood 2000). Underpinning these practices are prejudices about the worth and value of disabled people's lives, that these are lives not worth living (Morris 1991), which in turn leave disabled people feeling rejected and worthless. 
The gaze also exerts power over disabled people within everyday social interactions.

'We often experience the fascination that non-disabled people have with 'just how do you manage?' They have a consuming curiosity about how we pee, how we shit, how we have sex (do we have sex?) ... Our physical difference makes our bodies public property' (Morris 1991: 29; emphasis in original).

Having an impairment which is immediately visible presents the observer with privileged information and therefore power, about that body. This gaze is influenced by the stereotypes and prejudices about disabled people and so the power of the gaze is intimately linked and nourished by knowledge from within the social domain. Keith (1996) describes how people's reactions to her are informed by the wheelchair she uses; their assumptions about what it means to be a wheelchair user are so negative and different to how Keith sees herself, that she feels she needs to have ways of dealing with and understanding these encounters or 'they have the power to destroy me' (Keith 1996: 71).

Whilst acknowledging that the ways in which disabled people respond to the gaze of others vary and are affected by personal biographies and experience, nonetheless the disciplining power of the gaze can leave disabled people feeling ashamed, vulnerable and invalidated, and contributes to the psycho-emotional dimensions of disability. This particular form of disablism can prevent disabled people participating within society as much as the presence of structural barriers:

'It is not only physical limitations that restrict us to our homes and those whom we know. It is the knowledge that each entry into the public world will be dominated by stares, by condescension, by pity and by hostility' (Morris 1991: 25).

Because the power of the gaze arises from what can be seen by the observer, the experience of this form of disablism is affected by the visibility of impairment and impairment effects. Someone who cannot hide their impairment is exposed to the assumptions of others and their impairment often becomes their most significant personal attribute (French 1994a). On the other hand, someone with a hidden impairment is less subject to the power of the gaze and hence what others know about them; however, within the act of passing remains the fear of being discovered - 'the negative psycho-emotional aspects of concealment' (Thomas 1999a: 55). In addition, people with hidden impairments may attract hostility from others whilst using facilities provided for disabled people; for example when parking in a space reserved for disabled drivers.

Before considering some of the ways in which disabled people can resist the oppressive gaze of others I will explore a related technology of power, that of self-surveillance. 


\section{Self-surveillance}

The concept of self-surveillance developed out of the Panopticon, which was an ideal prison in which each isolated inmate lived knowingly under the continual inspection from the all-seeing, but anonymous eyes of the guard (Foucault 1977). This experience of living in permanent potential visibility led to the inmate internalising the scrutinising gaze, effectively and efficiently becoming selfpolicing. This process of self-surveillance is not restricted to institutions such as the prison or asylum, it exists throughout society, operating as a 'series of mechanisms for unbalancing power relations definitely and everywhere' (Foucault 1977: 223). Self-surveillance is therefore linked to the gaze - people develop an awareness of how they are seen through the gaze of another and then modify their behaviour via self-surveillance to attempt to make themselves acceptable. There are several different forms of self-surveillance which affect the psycho-emotional well-being of disabled people.

Self-surveillance of the physical body affects both disabled and non-disabled people. The terms 'healthy' and 'unhealthy' have become markers of moral worth, with people who do not look after their health being considered irresponsible and lacking self-control (Petersen 1997). As part of the rehabilitation process within spinal injury units, people with spinal cord injury are taught the principles of good bowel management and instructed how to check their bodies daily for signs of abrasion or pressure sores. Whilst I acknowledge that this returns autonomy to the disabled person for care of the self, literally to become a 'doctor of oneself' (Foucault 2000b: 235), failure to maintain an adequate level of self-care is considered by others to be irresponsible. From personal experience, it seems to me that the (usually) non-disabled people who criticise my failure to adhere to apparently simple self-surveillance tasks fail to appreciate the emotional costs of having to carry out tasks which they do not have to do themselves. These tasks are yet another reminder of my 'abnormality' and I am held responsible for failing to contain and render invisible that difference from the norm. I would consider that this form of self-surveillance of the body for some disabled people has an adverse effect on their emotional wellbeing.

Another use of self-surveillance is in the creation of disabled bodies when claiming benefit (Shildrick 1997). Disability Living Allowance (DLA) provides money for helping disabled people with their mobility and personal care needs. In the modern welfare state self-certification has replaced the traditional interview/assessment procedure. Rather than being under the gaze of the interviewer, the claimant is required to critically gaze upon their own body and report in detail how it fails to meet the 'norm'; in so doing, the claimant is creating themselves as disabled. Additionally it has been found that the chances of a successful DLA application are increased if a knowledgeable advocate completes the form, using particular forms of language which are recognised by the government agency (Daly and Noble 1996) - the self-surveillance of the body is constrained by how others describe disability. In a similar manner the applicant for Incapacity Benefit has to produce the incapable body and identify themselves as a disabled person incapable 
of work (Price and Shildrick 1998). The cost to the claimant of accepting these disability benefits is that they are forced to adopt the negative identity of a disabled person, someone who is abnormal and incapable; for many the emotional cost is too high and instead they prefer to manage without the financial benefits provided by the state.

The final example of self-surveillance I want to consider is that of internalised oppression - the ways in which disabled people internalise the prejudices and assumptions held by non-disabled people about them - which was described previously. In this form of self-surveillance disabled people may attempt to make themselves acceptable by conforming to the behaviour expected by non-disabled people and to adopt the 'disabled role' - being totally independent, 'normal', adjusted to their situation and taking full responsibility for managing social interactions (French 1994c: 48-56). By adopting this disabled role, disabled people become what they have internalised and the erroneous beliefs and attitudes about disabled people are never challenged (French 1994c). Unfortunately the disabled role can also be a contradictory one - whilst disabled people are perceived as being helpless, child-like and dependent, they are also seen as something to be feared and avoided (Evans 1992). Living a contradictory identity has a detrimental effect on the psycho-emotional well-being of a disabled person, causing stress and confusion, and in part, this conflicting identity remains unchallenged because of the lack of positive role models within society for disabled people. This particular form of self-surveillance, which usually operates at the unconscious level, is very difficult for individuals to identify and challenge.

Gaze and self-surveillance operate within the psycho-emotional dimensions of disability, a form of disablism that leaves disabled people feeling excluded, worthless, unattractive and stressed (Thomas 1999a). Although the practices and stereotypes which underpin this form of disablism are endemic within society, not all disabled people are passive recipients of this form of disability many exercise agency and resist.

\section{Challenging the psycho-emotional dimensions of disability}

Whilst gaze and self-surveillance are powerful forces which disable people with impairments, this form of disablism is not inevitable. Disabled people have been challenging these technologies of power and I will now discuss how these challenges can be related to the Foucauldian concepts of resistance and the related technologies of the self.

\section{Resistance}

As defined earlier, resistance emerges out of, and in opposition to power. Whilst this resistance may be radical, it is usually more localised and specific, mobilising people in different ways (Foucault 1981). One important example of resistance within the disabled people's movement has been the challenge of prevailing medical discourses about disability by the creation of the social model of disability. 
'The gaze is deflected, by disabled people, from impaired bodies to the social body which, hitherto a model of innocence, is now identified as the source of the disorder' (Hughes 1999: 159).

Another very obvious example is that provided by the activities of the Direct Action Network, disabled activists who use demonstrations to bring issues affecting disabled people, such as inaccessible transport, to the attention of the media and the general public (Campbell and Oliver 1996). Language has also been challenged by the use of the term 'non-disabled' instead of 'able-bodied', as a way of disrupting the stigma of disability and removing disabled people from the status of Other; how effective this challenge has been is debatable because the unequal power relations remain in place (Price and Shildrick 1998).

Whilst disciplinary power creates certain normalising practices which can be internalised as forms of self-surveillance, these very practices may result in resistance (Shildrick 1997). A good example of this is the way that disabled parents challenge the categories of parenting and caring (Keith and Morris 1996). The 'children as carers' stories which frequently appear in the media present the impression that children are parenting their parents. These stories ignore the reality about the wide variety of ways which disabled parents look after the emotional and physical needs of their children. Research on families with disabled parents has shown that it is usually lack of services and financial support which forces parents to rely on family members for support (Parker 1993). This research has also provided alternative understandings of what it means to be a parent or to care for someone, thereby challenging the hegemonic views of parenting and caring.

Resistance is also seen in the ways that disabled people are challenging the prevailing notions of beauty and physical perfection. The style magazine Dazed and Confused featured a group of disabled people modelling clothes designed by Alexander McQueen (Dazed and Confused 1998). In these pictures impairments were clearly visible and in several cases were an important part of the image; one model was a woman born without limbs modelling nude under coloured lights to resemble the Venus de Milo, a Greek sculpture of the perfect female body. This example shows disabled people returning the gaze back onto the reader - they refuse to be ashamed of revealing their impaired bodies. These images of disabled models are a far cry from the more usual modelling of mobility and incontinence aids.

Technologies of the self

Whilst resistance is a reaction to power, technologies of the self are about selftransformation and reflect an active, rather than a passive subject. There is obviously an overlap between these two terms because in many respects the disabled people who modelled in Dazed and Confused were resisting the norms about which bodies (tall, slim, non-disabled) feature in a style magazine at the same time as creating themselves as sexual, attractive people. As mentioned earlier, technologies of the self are not purely under the control of the individual cultural representations of disability together with the prejudices and attitudes of other people place restrictions 
on how far disabled people can transform themselves (Shakespeare 1994). Also it may be particularly difficult for disabled people to transform themselves given the very real physical effects and adverse consequences of ageing, sickness, disability and death (Williams and Bendelow 1999).

One example of a technology of the self are the ways in which disabled people can challenge their own internalised medical model of disability (Chadwick 1996). One set of responses to the negative stereotypes of disabled people involves denial where someone with an impairment will attempt to pass or be a 'supercrip', someone who is more than 'normal' (Shakespeare 1996). An alternative to this denial approach is to 'come out' as a disabled person, to claim the label in a positive manner through disability pride and to become part of a disability movement which offers a political and collective experience of disability (Shakespeare 1996). Coming out as a disabled person entails replacing the dominant medical model public narrative about disability with a social model narrative, as well as overcoming internalised oppression (Shakespeare, et al. 1996); this process of self-identification can be both liberating and emotionally painful (Thomas 1999b). However as discussed earlier, resisting by taking part in disability arts or politics means that the person has accepted a disabled identity which is not always trouble-free to adopt (Liggett 1988).

Challenges to the psycho-emotional (and structural) dimensions of disability have increased since the emergence of a disability movement and the social model of disability. A disability culture has grown which produces new disability narratives and brings disabled people together - opportunities to create a new disability identity (Shakespeare 1996). Technologies of power can create and maintain psycho-emotional disability and this form of disablism can be challenged through resistance and the self-transformation process of coming out as a disabled person. I will now explore the link between the experience of psycho-emotional disablism and disability identities drawing on Foucault's concept of subjectivity described earlier.

\section{Disability identities - a discussion}

Subjectivity was a term used by Foucault to describe the manner in which identity emerges from the interactions of discourses, ideologies and institutional practices rather than being a product of the self-governing conscious self (Danaher, et al. 2000). Thus the interplay of the different relations of power described previously together with current economic and socio-cultural processes are responsible for shaping a disability identity (Foucault 2000a).

Does a single disabled identity exist? Shakespeare (1996) considers this issue at length and concludes that in addition to the dangers associated with seeing disability as the primary identity of someone with an impairment (and ignoring their counter-identities such as gender, ethnicity, sexuality and age), it may also be necessary to consider a variety of disability identities, rather than a single essentialist disability identity. The concept of a single disability identity is appealing - disabled people linked by a shared experience of oppression and social exclusion - and as in other identity politics, it has political use as a rallying call to effect social change. However 
not all disabled people experience the same degrees of disabling barriers and discrimination: class, age, sexuality, gender and ethnic grouping affect the consequences of impairment and hence the social and economic experience of disability (Shakespeare 1996). The experience of structural disability is also affected by impairment; people with visual impairments will have different experiences of disability to those with mobility impairments (Shakespeare 1993).

Foucault warned against the dangers of privileging one form of identity over another (McNay 1992) and I believe that benefit would be gained from considering disability identity as multi-faceted and fluid, rather than a fixed concept. Throughout this paper I have shown how the psycho-emotional dimensions of disability are created and challenged by different technologies of power which operate from above and below. The relative strengths of these dominating and emancipatory forces are affected by personal experience, counter-identities as well as impairment; and like subjectivity, the daily experiences of the psycho-emotional dimensions of disability change according to the context disabled people find themselves in.

Thus, disability identities in part emerge from the experience of the psychoemotional dimensions of disability because of the construction of subjectivity from the interplay of technologies of power with resistance and technologies of the self. This experience of psycho-emotional disablism is interlinked with the experience of living with impairment effects (Thomas 1999a) and I have indicated some of the ways that impairment affects the psycho-emotional dimensions of disability, such as the manner in which the experience of the gaze is affected by the extent to which an impairment is visible or can be hidden. Therefore disability identity is a function of both disability and impairment experiences; it will be constituted differently for each individual and will have both temporal and spatial dimensions.

One of the reasons why people with impairments do not always identify with the disabled people's movement is because of the apparent downplaying of the role of impairment (Shakespeare 1993). Thomas (forthcoming) suggests that acknowledging the personal experiences of living with impairment and disability is politically unifying rather than divisive because it enables recognition of the range of disability experiences and how these are mediated by impairment and other intersecting identities such as gender and age. A social model of disability which includes both the structural and psycho-emotional dimensions of disability has much to offer the disabled people's movement because it acknowledges the personal experience of living with disability and impairment from a social, rather than individual theoretical standpoint. A fluid model of disability identity that acknowledges the personal experiences of disability and impairment supports this approach. In turn, this will make the disabled people's movement more relevant to people with impairments who do not currently identify as disabled.

\section{Conclusions}

The Foucauldian concepts of technologies of power, resistance and technologies of the self offer some insight into the psycho-emotional dimensions of disability and the manner in which they might be created, maintained and challenged. I have 
shown how gaze and self-surveillance are particularly powerful for describing the manner in which the bodies of disabled people are controlled and how this affects the emotional well-being of these people. However this control is not complete; disabled people can (sometimes) resist these particular technologies of power as well as transform themselves to generate different selves.

Like the differing experiences of structural disability, not all disabled people experience the same degrees of psycho-emotional disablism - personal biography, intersecting identities, impairment and context change the daily experiences of this form of disability. I am not saying that impairment causes structural or psycho-emotional dimensions of disability but rather that people with differing impairments will experience different consequences from these two different types of oppression.

The linking together of impairment and the psycho-emotional dimensions of disability is related to recent debates within disability studies about the dichotomy between disability and impairment. Corker and French (1999b) believe that disability and impairment are discursively related and so it is impossible to talk about the real experience of disability oppression whilst disability and impairment remain separated. Within everyday life, disabled people often describe a complex existence which occupies the space between disability and normality, health and illness which is not reflected in a disability studies approach which maintains the dichotomy and ignores this rich area between (Corker 1999a). Therefore I suspect that this interstitial area could offer valuable insight into the nature of psycho-emotional dimensions of disability experienced by disabled people.

Given that the disabled people's movement does not currently represent the full range of people with impairments (Shakespeare 1993), it may be appropriate to move away from the idea of a single, fixed disability identity. Disability identity needs to include aspects of both disability and impairment and to be more complex and inclusive if it is to better represent all disabled people in society. The psycho-emotional dimensions of disability underpin the concept of a fluid disability identity, an identity which is not fixed in time or place and which varies between disabled people. Resisting the psycho-emotional dimensions of disability and 'coming out' as a disabled person challenge the conventional denigrated disabled identities and are a form of individual political action.

'Relentless refusals to go along with what appears to come naturally are front-line battles in the politics of disability' (Liggett 1988: 274).

\section{Acknowledgements}

I am grateful for the encouragement of my supervisors Carol Thomas and Bob Sapey together with the financial support of an ESRC PhD studentship (R42200034345).

\section{References}

Allan, J. (1996) Foucault and Special Educational Needs: a 'box of tools' for analysing children's experiences of mainstreaming, Disability \& Society, 11, pp. 219-233. 
Bailey, R. (1996) Prenatal testing and the prevention of impairment: a woman's right to choose?, in: J. Morris (Ed.) Encounters with Strangers: Feminism and Disability (London, Women's Press).

Barnes, C. (1997) A Legacy of Oppression: A History of Disability in Western Culture, in: L. Barton and M. Oliver (Eds) Disability Studies: Past, Present and Future (Leeds, The Disability Press).

Campbell, J. and Oliver, M. (1996) Disability Politics: Understanding our past, changing our future (London, Routledge).

Chadwick, A. (1996) Knowledge, power and the Disability Discrimination Bill, Disability \& Society, 11 , pp. 25-40.

Corker, M. (1999a) Difference, conflations and foundations: the limits to 'accurate' theoretical representation of disabled people's experience?, Disability \& Society, 14, pp. 627-642.

Corker, M. (1999b) New disability discourse, the principle of optimization and social change, in: M. Corker and S. French (Eds) Disability Discourse (Buckingham, Open University Press).

Corker, M. and French, S. (Eds) (1999a) Disability Discourse (Buckingham, Open University Press).

Corker, M. and French, S. (1999b) Reclaiming discourse in disability studies, in: M. Corker and S. French (Eds) Disability Discourse (Buckingham, Open University Press).

Crow, L. (1996) Including all of our lives: Renewing the social model of disability, in: J. Morris (Ed.) Encounters with Strangers: Feminism and Disability (London, Women's Press).

Daly, M. and Noble, M. (1996) The reach of disability benefits: an examination of the disability living allowance, Journal of Social Welfare and Family Law, 18, pp. 37-51.

Danaher, G., Schirato, T. and Webb, J. (2000) Understanding Foucault (London, Sage Publications Ltd).

Dazed and Confused (1998) Access-Able, Dazed and Confused, (September) pp. 68-83.

Evans, J. (1992) Towards a disability imagery currency: Part 2 - Little Stephen - infantilism, projection and naturalism in the construction of mental disablement, in: D. Hevey (Ed.) The Creatures Time Forgot: Photography and Disability Imagery (London, Routledge).

Foucault, M. (1971) Madness and Civilisation: a History of Insanity in the Age of Reason (London, Tavistock).

Foucault, M. (1976) The Birth of the Clinic : An Archaeology of Medical Perception (London, Tavistock).

Foucault, M. (1977) Discipline and Punish: The Birth of the Prison (London, Penguin Books Ltd).

Foucault, M. (1980a) Body/Power, in: C. Gordon (Ed.) Power/Knowledge: Selected Interviews and Other Writings 1972-1977 (Brighton, The Harvester Press Ltd).

Foucault, M. (1980b) Two lectures, in: C. Gordon (Ed.) Power/Knowledge: Selected Interviews and Other Writings 1972-1977 (Brighton, The Harvester Press Ltd).

Foucault, M. (1981) The History of Sexuality: Volume 1, An Introduction (London, Penguin Books Ltd).

Foucault, M. (2000a) The ethics of the concern for self as a practice of freedom, in: P. Rabinow (Ed.) Michel Foucault Ethics: Subjectivity and Truth (Volume 1) (London, Penguin Books Ltd).

Foucault, M. (2000b) Technologies of the self, in: P. Rabinow (Ed.) Michel Foucault Ethics: Subjectivity and Truth (Volume 1) (London, Penguin Books Ltd).

Fox, N. J. (1993) Postmodernism, Sociology and Health (Buckingham, Open University Press).

French, S. (1993) Disability, impairment or something in between?, in: J. Swain, V. Finkelstein, S. French and M. Oliver (Eds) Disabling Barriers - Enabling Environments (London, Sage and Open University Press).

French, S. (1994a) Dimensions of disability and impairment, in: S. French (Ed.) On Equal Terms: Working with Disabled People (Oxford, Butterman-Heinemann Ltd).

French, S. (1994b) Disabled people and professional practice, in: S. French (Ed.) On Equal Terms: Working with Disabled People (Oxford, Butterman-Heinemann Ltd).

French, S. (1994c) The disabled role, in: S. French (Ed.) On Equal Terms: Working with Disabled People (Oxford, Butterman-Heinemann Ltd).

Hughes, B. (1999) The constitution of impairment: modernity and the aesthetic of oppression, Disability \& Society, 14, pp. 155-172. 
Hughes, B. and Paterson, K. (1997) The social model of disability and the disappearing body: towards a sociology of impairment, Disability \& Society, 12, pp. 325-340.

Keith, L. (1996) Encounters With Strangers: The public's responses to disabled women and how this affects our sense of self, in: J. Morris (Ed.) Encounters With Strangers: Feminism and Disability (London, Women's Press).

Keith, L. and Morris, J. (1996) Easy targets: A disability rights perspective on the 'children as carers' debate, in: J. Morris (Ed.) Encounters With Strangers: Feminism and Disability (London, Women's Press).

Liggett, H. (1988) Stars are not born: an interpretive approach to the politics of disability, Disability, Handicap \& Society, 3, pp. 263-275.

Marks, D. (1999) Disability: controversial debates and psychosocial perspectives (London, Routledge).

Mason, M. (1992) Internalised oppression, in: R. Rieser and M. Mason (Eds) Disability Equality in the Classroom: A Human Rights Issue, 2nd edn (London, Disability Equality in Education).

Mclntosh, P. (2002) An archi-texture of learning disability services: the use of Michel Foucault, Disability \& Society, 17, pp. 65-79.

McNay, L. (1992) Foucault and Feminism: Power, Gender and the Self (Cambridge, Polity Press in association with Blackwell Publishers, Oxford).

Morris, J. (1991) Pride Against Prejudice: Transforming Attitudes to Disability (London, Women's Press).

Oliver, M. (1990) The Politics of Disablement (London, Macmillan).

Oliver, M. and Barnes, C. (1998) Disabled People and Social Policy: From Exclusion to Inclusion (Harlow, Addison Wesley Longman).

Oliver, M., Zarb, G., Moore, M., Silver, J. and Salisbury, V. (1988) Walking into Darkness: the Experience of Spinal Injury (London, Macmillan).

Parker, G. (1993) With This Body: Caring and Disability in Marriage (Buckingham, Open University Press).

Petersen, A. (1997) Risk, governance and the new public health, in: A. Petersen and R. Bunton (Eds) Foucault, Health and Medicine (London, Routledge).

Pheterson, G. (1986) Alliances between women: Overcoming internalised oppression and internalised domination, Signs: Journal of Women in Culture and Society, 12, pp. 146160.

Price, J. and Shildrick, M. (1998) Uncertain Thoughts on the Dis/abled Body, in: M. Shildrick and J. Price (Eds) Vital Signs: Feminist Reconfigurations of the Bio/logical Body (Edinburgh, Edinburgh University Press).

Shakespeare, T. (1993) Disabled People's Self-organisation: a new social movement?, Disability, Handicap and Society, 8, pp. 249-264.

Shakespeare, T. (1994) Cultural Representation of Disabled People: dustbins for disavowal?, Disability \& Society, 9, pp. 283-299.

Shakespeare, T. (1996) Disability, Identity, Difference, in: C. Barnes and G. Mercer (Eds) Exploring the Divide: IIIness and Disability (Leeds, The Disability Press).

Shakespeare, T., Gillespie-Sells, K. and Davies, D. (1996) The Sexual Politics of Disability: Untold Desires (London, Cassell).

Shildrick, M. (1997) Leaky Bodies and Boundaries: Feminism, postmodernism and (bio)ethics (London, Routledge).

Sullivan, M. and Munford, R. (1998) The articulation of theory and practice: critique and resistance in Aotearoa New Zealand, Disability \& Society, 13, pp. 183-198.

Thomas, C. (1999a) Female Forms: Experiencing and Understanding Disability (Buckingham, Open University Press).

Thomas, C. (1999b) Narrative identity and the disabled self, in: M. Corker and S. French (Eds) Disability Discourse (Buckingham, Open University Press).

Thomas, C. (forthcoming) Feminism and disability: the theoretical and political significance of the personal and the experiential, in: L. Barton (Ed.) Disability, Politics and the Struggle for Change (London, Patrick Armstrong). 
Williams, S. J. and Bendelow, G. (1999) The Lived Body: Sociological Themes, Embodied Issues (London, Routledge).

Wood, R. (2000) Is the NHS killing us?, Disability Now, (July) p. 13.

Woolley, M. (1991) Acquired Hearing Loss: Acquired Oppression, in: G. Taylor and J. Bishop (Eds) Being Deaf: The Experience of Deafness (London, Pinter Publishers in association with The Open University). 